\title{
Desenvolvendo um processo de análise de investimentos baseado em competências
}

\author{
Developping an investimento analysis \\ process based on competences
}

\author{
Ronald Nieweglowski ${ }^{1}$ \\ Edson Pinheiro de Lima² \\ Sergio Eduardo Gouvea da Costa ${ }^{2}$
}

\begin{abstract}
Resumo: O conjunto de competências organizacionais que uma empresa emprega na realização de suas operações, potencialmente define sua capacidade de realizar uma determinada estratégia de negócios. O presente artigo se propõe a desenvolver um processo para a análise de projetos de investimento baseado em competências. O estudo se desenrola no âmbito das pequenas empresas e se aplica a projetos de expansão da capacidade. A abordagem desenvolvida fundamenta-se na construção de um framework teórico-conceitual, sendo este refinado por um conjunto de entrevistas realizadas com especialistas. Participam das entrevistas três analistas pleno de investimento e três acadêmicos das áreas de gestão estratégica de operações e gestão econômica da produção. O processo desenvolvido é testado em casos de simulação que se utilizam de dados obtidos de três projetos de investimento analisados por um banco de desenvolvimento, no período de março de 2002 a setembro de 2003. Os casos se distribuem entre os setores de manufatura, comércio de serviços. O resultado do trabalho é um processo de análise de investimentos que usa o conceito de competências empresariais para avaliar a capacidade de uma empresa em gerar resultados. O processo desenvolvido vincula recursos e competências à estratégia empresarial adotada, avaliando as condições necessárias para o desenvolvimento da estratégia. O estudo é de natureza exploratória e, portanto, não permite generalizações. Há necessidade de se ampliar o número de simulações e testar o uso do processo com diferentes analistas de investimento. A principal implicação prática do trabalho reside no fato de se propor um procedimento estruturado para a análise de projetos de investimento para pequenas empresas, dadas as dificuldades de se obter informações econômico-financeiras destas empresas. A pesquisa realizada contribui para o desenvolvimento de metodologias para análise de projetos de investimento, fundamentando-se em uma abordagem de natureza estratégica.
\end{abstract}

Palavras-chave: Análise de investimentos. Gestão de projetos. Estratégia empresarial. Teoria baseada em recursos. Competências empresariais. Estratégia de operações.

\begin{abstract}
The organisational competences that an enterprise uses in its operations potentially define its capacity for implementing its business strategy. The present paper proposes a process for the analysis of investment projects based on competences. The study is focused on small enterprises, and it is applied to capacity expansion projects. The developed approach is based on a theoretical framework refined through a round of interviews conducted with experienced professionals. Three investment analysts and three academics that work in the strategic operations management and economic production management areas participated in the interviews. The developed process was tested in simulation studies using the results of three investment projects analyzed by a development bank in the period of March 2002 to September 2003. The cases are related to manufacturing, commerce, and service sectors. The result of this work is an investment analysis process that uses the enterprise competences concept to evaluate its capability to generate results. The process relates resources and competences to the adopted business strategy. The study nature is exploratory and, in this sense, it does not allow generalizations. It is necessary to increase the number of simulations and to test the process using different investment analysts. The major practical implication is related to the fact that a structured procedure was proposed for the analysis of investment projects for small companies due to the difficulty of obtaining accurate and reliable financial and economic information about those companies. This study contributes to the development of methodologies for the analysis of investment projects based on a strategic approach.
\end{abstract}

Keywords: Investment analysis. Project management. Business strategy. Resource based theory. Enterprise competences. Operations strategy.

\footnotetext{
Programa de Pós-Graduação em Engenharia de Produção e Sistemas, Pontifícia Universidade Católica do Paraná - PUCPR, Curitiba - PR, Brasil, E-mail: slmandic@bbs2.sul.com.br

${ }^{2}$ Programa de Pós-Graduação em Engenharia de Produção e Sistemas, Pontifícia Universidade Católica do Paraná - PUCPR, Universidade Tecnológica Federal do Paraná - UTFPR, Curitiba - PR, Brasil, E-mails: e.pinheiro@ pucpr.br; s.gouvea@pucpr.br

Recebido em 4/8/2007 — Aceito em 26/4/2010
}

Suporte financeiro: Fundo de Pesquisa da Pontifícia Universidade Católica do Paraná. 


\section{Introdução}

Num mundo globalizado, no qual a concorrência do mercado empresarial torna-se cada vez mais intensa, as empresas necessitam melhorar o seu desempenho e ampliar as suas áreas de atuação, buscando cotidiana e ativamente novas formas de operacionalização de suas unidades de negócio, otimizando e integrando recursos existentes e racionalizando a utilização de valores monetários, quando da aplicação em novos investimentos. O dinamismo gerado por esta imposição mundial tem proporcionado o avanço de teorias e instrumentos de gestão da produção, refletindo nos procedimentos operacionais de organizações comerciais, industriais e de serviços. Porém, no desempenho de instituições bancárias e financeiras, fundamentais para fornecimento de crédito aos diversos setores, observa-se grande interesse na automatização dos processos, procurando reduzir custos e aumentar o volume de transações. Contudo, pouca atenção tem sido dedicada à pesquisa de modelos para qualificar meios de análise visando concessão de empréstimos e financiamentos de longo prazo, nos quais há necessidade de uma sistematização da coleta e interpretação de dados que possibilite, após sua avaliação, a tomada de uma decisão que, normalmente, envolve altos valores e um longo período para retorno dos capitais aplicados, o que torna a análise de investimento uma atividade de riscos potenciais para fornecedores de crédito (MENOR; ROTH, 2007; CHAUMON; DUBOIS; RETOUR, 2006; LEACHMAN; PEGELS; SHIN, 2005; RUSJAN, 2005; LAMARQUE, 2004; CASAROTTO FILHO, 2002; CASAROTTO FILHO; KOPITTKE, 2000).

Há, portanto, a necessidade de processos de análise de investimento que permitam às instituições de crédito avaliar a capacidade das empresas em gerar resultados. Uma análise de tal natureza pode ser feita pela identificação das competências que uma empresa possui ou necessita desenvolver para realizar a sua estratégia. Tal abordagem pode ser considerada 'estratégica', sendo desenvolvida no âmbito da "Teoria baseada em Recursos, Capacitações e Competências". Na área de Gestão de Operações, há diversos estudos recentes cujo objetivo é compreender as relações de causa e feito que se estabelecem entre capacitações e/ou competências organizacionais e desempenho. Conhecer tais implicações em uma empresa permite avaliar a sua capacidade de gerar resultados (SWINK; NARASIMHAN; KIM, 2005; LEACHMAN; PEGELS; SHIN, 2005; GONZALEZBENITO, 2005; ESCRIG-TENA; BOU-LLUSAR, 2005; BROWN; BLACKMON; LEUNG; LEE, 2004; KATHURIA; PORTH, 2003).

$\mathrm{O}$ presente artigo desenvolve um processo para análise de projetos de investimento, no âmbito da expansão de capacidade, utilizando uma abordagem de natureza estratégica fundamentada na Teoria baseada em Recursos. São estudadas empresas de pequeno porte e o nível de análise é o das suas operações na produção de um bem ou na prestação de um serviço (WOILER; MATHIAS, 1985; BRASIL, 2002).

$\mathrm{O}$ artigo inicialmente apresenta a base conceitual a ser utilizada, para então desenvolver e 'refinar' um processo de análise de investimento, utilizando para tanto, um conjunto de entrevistas com especialistas na área de projetos de investimento, gestão estratégica de operações e gestão econômica da produção. Desenvolvido o processo, ele é testado em um conjunto de três casos, abrangendo projetos de investimento em pequenas empresas na indústria, no comércio e em serviços. Busca-se, portanto, explorar diferentes setores econômicos, que representam a grande maioria dos projetos de investimento atendidos pelo banco de desenvolvimento estudado. Também é representativa a natureza dos pedidos, que se fundamentam em projetos de expansão (BROWN; BLACKMON, 2005).

\section{A análise de investimentos}

Para que se construa uma perfeita compreensão do escopo e do propósito deste trabalho, torna-se importante a definição de alguns termos básicos. Considera-se 'projeto' como

o conjunto de informações internas e/ou externas à empresa, coletadas e processadas com o objetivo de analisar-se (e, eventualmente, implantar-se) uma decisão de investimento (WOILER; MATHIAS, 1985, p. 26).

Empresas, bancos, investidores e fornecedores utilizam-se da análise de projetos de investimentos para determinar a viabilidade do empreendimento e, assim, os possíveis níveis de aplicação de capital ou concessão de crédito monetário para participação ou financiamento da execução do projeto.

Para Esty (2008), um projeto de investimento fundamenta-se em três aspectos básicos: o investimento em um determinado tipo de ativo; uma 'organização' para o gerenciamento do investimento; um conjunto de patrocinadores que irão financiar a iniciativa. Dimova, Sevastianov, Sevastianov (2006) destacam o aspecto multivariável na avaliação de projetos de investimento que podem envolver questões relacionadas à viabilidade econômica e ao alinhamento estratégico, dentre outros diversificados aspectos. Gotze, Northcott e Schuster (2008) classificam os projetos de investimento em: criação de um novo empreendimento; adequação do empreendimento atual face a necessidades de relocalização ou de modernização; suplementares no que se refere a expansão ou ampliação do empreendimento atual.

O Quadro 1 apresenta uma classificação para os projetos de investimento, considerando tipos de investimentos sob o ponto de vista microeconômico. 
Quadro 1. Projetos de investimento.

\begin{tabular}{|ll|}
\hline \multicolumn{1}{|c|}{ Tipos } & \multicolumn{1}{c|}{ Descrição } \\
\hline Implantação & Instalar um empreendimento totalmente novo e independente de outros processos \\
Relocalização & Verificar as mudanças necessárias para continuidade ou melhoria das operações \\
Modernização & Desenvolver melhorias em antigos empreendimentos \\
Ampliação ou expansão & Aumentar a capacidade de linhas de produção e diversificar a oferta de novos produtos \\
\hline
\end{tabular}

Fonte: Woiler e Mathias (1985, p. 27).

Casarotto Filho e Kopittke (2000, p. 288) destacam que

definir projetos de investimento em uma empresa é decorrência da intenção empresarial, ou seja, a intenção de seus colaboradores, dirigentes e até, porque não, de seus colaboradores. A intenção empresarial, enquanto fruto de um planejamento, passa a se chamar Estratégia Empresarial.

O projeto de investimento é, portanto, um 'instrumento' para a realização da estratégia empresarial, e segundo Matheus (2000, p. 2), contribui para:

Uma vez definida a utilização de projetos como forma de administrar e realizar os negócios de uma organização, mais clara e objetiva se torna a questão da definição e alcance dos objetivos (resultados) almejados pela empresa, sendo estes uma somatória - sinérgica ou não - dos resultados obtidos em cada projeto, que devem estar, portanto, alinhados com os objetivos da empresa, e estes, por sua vez, com as diretrizes estratégicas definidas pela organização.

Os resultados da análise de projetos de investimento são utilizados pelas empresas interessadas que, por sua vez, representam o próprio objeto de estudo; também interessam aos seus fornecedores de produtos e serviços, bem como aos seus clientes. No entanto, são de particular interesse aos investidores e às instituições responsáveis pela concessão de crédito (instituições bancárias). Considerando o papel das instituições bancárias neste processo, Santos (2000, p. 20) estabelece que:

A principal atividade dos bancos é a intermediação de recursos. Os bancos captam recursos de seus clientes e do mercado (financeiro e de capitais), repassando-os posteriormente sob a forma de empréstimos, na expectativa de realizarem ganhos, aqui denominados spread - diferença entre o custo de captação e o custo de repasse. Nesse processo, o risco total corresponde à condição de não recebimento dos empréstimos, em face da concessão de crédito para clientes de alto risco.

Sob o ponto de vista normativo, o Banco Central do Brasil, por meio da Resolução no 2.682 e normas complementares, considera como critérios básicos à concessão de apoio financeiro uma análise técnica, econômica, financeira e jurídica do projeto ou empreendimento a ser beneficiado. As análises devem evidenciar os seguintes requisitos mínimos (BANCO CENTRAL DO BRASIL, 2003): existência de mercado para os bens e/ou serviços a serem produzidos; exequibilidade técnica do processo de produção e disponibilidade dos demais recursos; capacidade de pagamento do beneficiário; garantias suficientes; capacidade empresarial do grupo empreendedor; ficha cadastral satisfatória da empresa, dos administradores e principais acionistas e sócios.

Como pode ser observado, vários são os aspectos a serem analisados, e uma consequência direta deste processo é a complexidade estrutural associada. A complexidade inerente ao sistema estudado dificulta a análise da capacidade de gerar valor dos empreendimentos sob análise. De acordo com Silva (2000, p. 132):

Os serviços de análise, propriamente ditos, consistem em interpretar e analisar de forma conjunta os dados disponíveis de uma empresa e emitir parecer sobre a sua situação econômico-financeira. O principal instrumento para desenvolvimento deste trabalho são os demonstrativos contábeis padronizados, de onde o analista irá avaliar a situação da empresa, por meio da evolução das contas e da interpretação dos índices financeiros, verificando os motivos das melhoras ou das pioras ocorridas, bem como examinando a adequação das captações e aplicações de recursos, da eficiência das políticas de vendas, compras e estocagem.

Micro e pequenas empresas, assim consideradas por faturamentos anuais iguais ou inferiores a R \$ 1,2 milhão, podem beneficiar-se do Sistema Integrado de Pagamento de Impostos e Contribuições das Microempresas e das Empresas de Pequeno Porte (SIMPLES), estando dispensadas de apresentar escrituração 'contábil'. Em razão da não obrigatoriedade por parte de micro e pequenas empresas da apresentação de documentos formalizados, como balanços patrimoniais, há muita heterogeneidade no modo de oficialização de dados deste setor.

Diante dos elementos apresentados, justifica-se o desenvolvimento de um processo de análise de investimento que identifique a real 'capacidade' de um empresa em geral 'resultados', dada a sua estratégia empresarial, recursos e competências, particularmente no que se refere a micro e pequenas empresas. 


\section{Análise estratégica}

Segundo Chandler; MacCraw (1998, p. 13),

estratégia pode ser definida como a determinação de metas e objetivos básicos de longo prazo de uma empresa, e a adoção de cursos de ação e alocação de recursos necessários para atingir estas metas.

Quinn (1980, p. 20) define estratégia de uma maneira particularmente importante ao presente trabalho:

o padrão ou plano que integra as principais metas, políticas e sequência de ações de uma organização em um todo coerente. Uma estratégia bem-formulada ajuda a ordenar e alocar os recursos de uma organização para uma postura singular e viável, com base em suas competências e deficiências internas relativas, mudanças antecipadas no ambiente e providências contingentes realizadas por oponentes inteligentes.

Andrews (1980, p. 59) destaca não só o aspecto da formulação, mas acrescenta também a necessidade da implantação correta da estratégia:

A estratégia empresarial é um processo organizacional, de várias maneiras inseparável da estrutura, do comportamento e da cultura da companhia na qual é realizada. Não obstante, podemos extrair desse processo dois aspectos importantes, inter-relacionados na vida real, mas separáveis para efeitos de análise. O primeiro poderá ser chamado de formulação e o segundo, de implementação. Decidir qual estratégia deve ser abordada com empreendimento racional, mesmo que tenha ligações emocionais [...] poderá complicar a escolha de alternativas futuras.

Este trabalho procura alinhar a escola racionalista a uma abordagem mais aderente à verificação do uso de recursos e competências internas da empresa. Propõe-se utilizar da análise SWOT somada à Teoria baseada em Recursos, Capacitações e Competências (O'REGAN; GHOBADIAN, 2004; KETOKIVI; SCHROEDER, 2004; FLEURY, A. C. C.; FLEURY, M. T. L., 2004; GAGNON, 1999; BARNEY, 1991; WERNERFELT, 1984; PENROSE, 1959).

O conteúdo da estratégia pode ser considerado genericamente como o conjunto de políticas, planos e comportamentos que a empresa pretende seguir. No nível da função produção, Leong, Snyder e Ward (1990) organizam o conteúdo da estratégia de produção em: 'áreas de decisão' e 'prioridades competitivas' . Hayes e Wheelwright (1984) classificam as áreas de decisão em: estruturais, considerando a capacidade de produção, instalações, tecnologia de processo e integração vertical; e de infraestrutura, como o planejamento e controle de produção, políticas de qualidade, estrutura organizacional, recursos humanos, desenvolvimento de novos produtos e sistema de medição de desempenho. Para Leong, Snyder e Ward (1990), as dimensões competitivas ou objetivos de desempenho podem estar relacionados a: custo, qualidade, desempenho de entrega, flexibilidade e inovatividade.

Segundo Wright, Kroll e Parnell (2000, p. 86), o enfoque em recursos permite à administração formular estratégias realistas para que seus objetivos sejam atingidos. Os pontos fracos e fortes de uma empresa constituem seus recursos. Incluem os recursos humanos, recursos organizacionais e recursos físicos.

\section{Recursos e competências}

Mills et al. (2002, p. 5) classificam os recursos em: recursos tangíveis; recursos e valores culturais; recursos de sistemas e processos; recursos de conhecimento, habilidades e experiência; recursos importantes para mudança. Mills, Platts e Bourne (2003b) utilizam-se de três métricas para avaliar um recurso: valor percebido pelos clientes; sustentabilidade do valor; e versatilidade do seu uso.

Sanchez (1997) destaca que, em contraste com o tradicional foco em bens tangíveis, entendidos como capacidade de produção, a análise estratégica baseada em competência também reconhece a importância 'estrutural' de bens intangíveis como conhecimento. Jurie (2000) e Sanchez (1997) desenvolvem o conceito de competência no nível organizacional. Para Sanchez (1997), competência é a habilidade de uma organização para sustentar combinações de recursos que promovam condições da organização alcançar suas metas. A distinção técnica entre os termos competência e capacitação, muitas vezes são muito tênues.

Para Prahalad e Hamel (1990) competências essenciais seriam resultantes do aprendizado coletivo na organização, especialmente no que se refere a coordenar diversas habilidades de produção e integrar múltiplas tecnologias. Estes autores consideram a empresa como um portfólio de competências.

As vantagens de uma análise eficaz das competências no nível das operações pode implicar na identificação do potencial de se realizar determinada estratégia (SCHMENNER; VASTAG, 2006; MILLS; PLATTS; BOURNE, 2003a; DAVIS; AQUILANO; CHASE, 1999, p. 52).

Se as competências existentes fundamentam a estratégia em desenvolvimento, o desenvolvimento de novas competências, por meio de projetos de investimentos, pode permitir ao solicitante de recursos manter uma boa situação mercadológica ou atingir novos mercados. Para Post (1997), uma estratégia fundamentada no desenvolvimento de competências estabelece os fundamentos para competir no futuro. É condição necessária identificar as competências 
para a realização de determinada estratégia, mas não é suficiente. Deve-se também definir o nível de desenvolvimento para as competências.

Chiesa e Manzini (1997) consideram os seguintes níveis de desenvolvimento para as competências de uma empresa: $1^{\circ}$ nível de competência, visão das capacitações da empresa (identificação das capacitações e compreensão do contexto); $2^{\circ}$ nível de competência, capacitações distintivas (capacidade de repetição de padrões de ação); e $3^{\circ}$ nível de competência, no uso das capacitações distintivas na produção. Purcell e Gregory (1998) propõem uma matriz de competências baseada em quatro processos: seleção, proteção, construção e melhoramento de competências.

Baseando-se nos estudos de Winter (1987), que distinguem a possibilidade de classificação de capacitações entre essenciais e necessárias, Drejer e Riis (2000) estabelecem os níveis de desenvolvimento de competências em: noviço, iniciante avançado, proficiente, perito e de classe mundial.

Buscando desenvolver um modelo analítico para o estudo das competências empresariais, Band (1997) identificou dez competências críticas a serem desenvolvidas para que uma empresa atinja alto desempenho: criação de valor, redesenho dos processos de negócios, mudança da arquitetura da empresa, envolvimento no ambiente de trabalho, parcerias, tecnologia, alinhamento da estratégia, aprendizado na organização, gerenciamento para mudanças e liderança. Também por meio de um enfoque geral, Ferraz et al. (2001, p. 3) consideram quatro áreas de competência empresarial para análise de competitividade: gestão, inovação, produção e recursos humanos.

Para McGrath et al. (1995), o processo de desenvolvimento de competências estabelece uma trajetória evolutiva de como as empresas atingem os seus objetivos estratégicos. O conjunto de competências organizacionais que uma empresa emprega na realização de suas operações define, potencialmente, a capacidade de uma organização em realizar determinada estratégia de negócios. A identificação de tais competências permite, portanto, avaliar as condições necessárias para a realização de estratégia definida.

Tratados os fundamentos teóricos para o desenvolvimento do processo de análise de investimento baseado em competências, pode-se apresentar a estratégia metodológica.

\section{Desenvolvimento da pesquisa}

A pesquisa realizada envolve tanto aspectos qualitativos como também quantitativos. Qualitativos, por apoiar-se na opinião de especialistas quanto à proposição de um processo que considera aspectos estratégicos na avaliação de projetos de investimento. $\mathrm{O}$ aspecto quantitativo se torna presente nas simulações realizadas, muito embora não posam ser utilizados os resultados para fins de generalização. Dada a natureza do trabalho, empregam-se instrumentos como: entrevistas para refinamento do modelo de análise inicialmente elaborado; e a simulação de análise de projetos de investimento para observação da efetividade do processo refinado pelos especialistas. A estratégia de pesquisa fundamenta-se na sistematização de um processo e o seu teste (PLATTS et al., 1998).

Na primeira etapa da pesquisa, o processo de análise foi desenvolvido por meio da construção de um modelo teórico, bem como se utilizando de um conjunto de entrevistas semiestruturadas (ALVES, 2003, p. 63).

As entrevistas foram organizadas e realizadas em dois grupos. O primeiro, com três profissionais de análise de investimentos com mais de dez anos de experiência, dado que os investimentos normalmente têm um período longo para retorno do capital aplicado - os prazos básicos para pagamento são de 60 (sessenta) meses -, ou seja, para observar o sucesso ou insucesso de uma quantidade apreciável de investimentos em segmentos diversos, os quais se pretendeu analisar neste trabalho, o profissional da área deve possuir uma experiência mínima de dois ciclos de análises completas, suprindo a necessidade do ponto de vista prático da transposição desta abordagem teórica para a prática.

Ainda na primeira etapa, três acadêmicos com experiência em pesquisas nas áreas de gestão estratégica de operações e gestão econômica da produção foram entrevistados. Participaram pesquisadores com amplo conhecimento teórico, e também com larga vivência na orientação de pesquisas científicas, para refletir se os estudos escolhidos como base para montagem do modelo apresentavam-se adequados para atingir os objetivos pretendidos, e possíveis alternativas para melhoria da metodologia de pesquisa.

$\mathrm{Na}$ segunda etapa, foram feitas simulações de análises de investimentos, utilizando-se de dados provenientes de três processos reais de análise de investimentos, de pequenas e médias empresas, oriundas de três diferentes segmentos - comércio, indústria e serviço - analisados por metodologias tradicionais de uma instituição financeira repassadora de recursos provenientes do BNDES, e observações provenientes de visitas técnicas (UPTON; MACADAM, 1997).

As informações obtidas junto às entrevistas e aos testes nos três diferentes casos constituem elementos básicos para a evolução do framework teórico-conceitual construído com base na teoria. Esta interação permitiu a evolução do processo proposto, garantindo a qualidade científica da pesquisa por intermédio da triangulação entre evidências empíricas, análise dos resultados das simulações 
pelos pesquisadores e do referencial teórico utilizado (LEWIS, 1998).

Considerando a grande amplitude da análise de projetos de investimentos, o estudo é delimitado pelas análises de crédito bancárias. As empresas são estudadas em diferentes segmentos para investigar de maneira exploratória os benefícios e dificuldades imediatas do uso do processo em cada setor. As pequenas empresas constituíram o objeto de estudo, dada a importância de se estudar a análise de crédito para este segmento de empresas, observada a não obrigatoriedade de formalização dos informes de desempenho econômico e financeiro. A abrangência da pesquisa também é definida pela natureza do projeto e, para tanto, escolheram-se projetos de expansão das operações. Uma das intenções da pesquisa é estudar as relações que se estabelecem entre recursos e a formação de competências organizacionais, visto que fundamentam a capacidade de uma empresa realizar determinada estratégia e, por conseguinte, obter determinado desempenho.

\section{Análise por competências}

Esta seção apresenta o desenvolvimento de um processo para a análise de investimento baseado em competências (Figura 1). A abordagem utilizada para a concepção do processo é de origem estratégica e fundamenta-se na teoria baseada em recursos, capacitações e competências (BOUCHER et al., 2007; CHEN; WU, 2007; FLEURY, A. C. C.; FLEURY, M. T. L., 2003; CASAROTTO FILHO; KOPITTKE, 2000, p. 288).

Para o desenvolvimento do processo de análise de investimentos, pelo estudo e valoração das competências empresariais, considera-se necessário, além de contemplar os fatores relacionados pelo Banco Central do Brasil (2003) para análise de operações de financiamento, sistematizar os diversos estudos sobre identificação e análise de competências que foram selecionados a partir da revisão de literatura (LEWIS, 2003; MILLS et al., 2002, 2003a, 2003b). O objetivo é formar um sistema de análise que promova a utilização da teoria de recursos, capacitações e competências na análise de projetos de investimentos.

O processo de análise de investimentos proposto neste trabalho busca entender a integração dos recursos solicitados com a estratégia do negócio. Não obstante, para permitir que o sistema proposto esteja compatível com a realidade das pequenas empresas, a estratégia destas organizações será analisada como um todo, ou seja, não será desdobrada funcionalmente. Tal abordagem se justifica pelo fato de que estas empresas não têm uma 'componente administrativa' adequadamente desenvolvida, isto é, não há formação de unidades de negócio e as unidades organizacionais estão fundamentadas nas funções básicas (produção, financeiro e comercial) (STONEHOUSE; PEMBERTON, 2002).

O processo de análise de investimentos se inicia com o desenvolvimento de uma análise de natureza técnica, econômica, financeira e jurídica do projeto ou empreendimento a ser beneficiado. Estes procedimentos cumprem as normas estabelecidas pela Resolução $\mathrm{n}^{\circ} 2.682$ do Banco Central do Brasil (BANCO CENTRAL DO BRASIL, 2003).

Com o objetivo de realizar uma análise estratégica preliminar, o processo de formulação da estratégia empresarial é estudado visando identificar: quem são os responsáveis pelo processo; quem são os atores envolvidos; como se organiza o processo, ou seja, verifica-se se um modelo formal para a formulação da estratégia é adotado e se estabelece uma sequência temporal de eventos na forma de um cronograma; quais são as partes da organização analisadas no processo; quais são as fontes de dados utilizadas para formular estratégia empresarial (OLIVEIRA, 2003).

Conhecida a arquitetura estratégica da empresa, os recursos e competências necessários para a sua realização podem ser estudados. Inicialmente, identificam-se os recursos existentes, qualificando-os em termos de valor, sustentabilidade e versatilidade, conforme será mostrado adiante no Quadro 7. Os recursos identificados também são classificados em tangíveis e intangíveis (MILLS et al., 2002).

Após a caracterização da qualidade e importância dos recursos disponíveis e de posse da análise de dados operacionais da empresa (análise técnica, econômica, financeira e jurídica), as competências empresariais podem ser identificadas e declaradas. As competências, segundo Prahalad e Hamel (1990), devem permitir o aprendizado coletivo, ser difíceis de serem imitadas e oferecer vantagens percebidas aos clientes. Trabalhando na perspectiva de projetos de investimento para expansão e/ou modernização do negócio, pode-se ainda, estudar a possibilidade do desenvolvimento de um novo produto ou processo produtivo.

Além da declaração das competências organizacionais desenvolvidas ou a desenvolver, é importante saber em que nível se encontram e, para tanto, utilizou-se dos modelos desenvolvidos por Winter (1987) e Drejer e Riis (2000) que apresentam um tipo de 'escala de maturidade'. Os níveis classificam-se em: básico, intermediário, avançado e de classe mundial. Estes níveis podem ser avaliados em termos de: necessidade de desenvolvimento, em desenvolvimento, desenvolvido e competência essencial.

Para concluir o processo de análise, levanta-se o conteúdo da estratégia. O conteúdo da estratégia é definido por uma análise do tipo SWOT (oportunidades e ameaças, pontos fortes e pontos fracos) em que a estratégia de negócios é definida (OLIVEIRA, 2003; ANSOFF, 1990). 
Complementarmente à análise SWOT, são identificadas as políticas e ações implementadas nas diferentes áreas de decisão do sistema de produção. Este levantamento é desenvolvido no âmbito da cadeia de valor, ou seja, no nível do sistema de produção. São estudadas as dimensões estruturais: capacidade produtiva, instalações, tecnologia de processo e integração vertical; e de infraestrutura: planejamento e controle da produção, políticas de qualidade, estrutura organizacional, recursos humanos, desenvolvimento de novos produtos e o sistema de medição de desempenho (HAYES; WHEELWRIGHT, 1984).

Os estudos que definem o conteúdo da estratégia empresarial, nas dimensões do negócio e da função produção, são concluídos com a formalização das prioridades competitivas. O conhecimento das prioridades competitivas da empresa permite observar se os investimentos futuros, ou seja, se os recursos que a empresa pretende adquirir são coerentes com os recursos existentes e a estratégia estabelecida (SLACK, 2002).

Para que se possa desenvolver uma apreciação do mérito dos investimentos, são identificados e avaliados os recursos e competências que a empresa deve desenvolver, utilizando os mesmos procedimentos para os recursos e competências existentes. Esta nova análise é realizada com a projeção da aquisição dos recursos pretendidos e o estudo do impacto, proveniente da incorporação destes novos recursos, nas operações da empresa.
O processo de análise de investimento é finalmente concluído e um parecer conclusivo é gerado. Adicionalmente, também são propostos instrumentos auxiliares para a avaliação e gestão dos recursos solicitados, na forma de um fluxo de caixa simplificado e de indicadores econômico-financeiros (taxa interna de retorno, valor presente líquido e período de recuperação do investimento).

A Figura 1 organiza, na forma de um processo, os procedimentos propostos para a análise de investimento baseada em competências.

A proposta apresentada na Figura 1 fundamenta-se nos modelos tradicionais de investimento e acrescenta um componente de análise estratégico. Tal componente visa avaliar o potencial de dado projeto em realizar determinada estratégia empresarial. A avaliação fundamenta-se em uma análise interna das competências desenvolvidas e a desenvolver.

Definido o processo, nas suas diferentes etapas e atividades, identificados os procedimentos operacionais a serem adotados, pode-se, então, trabalhar o seu refinamento. A estratégia de refinamento baseia-se em um conjunto de entrevistas com especialistas na análise de investimentos.

\section{Refinamento do processo de análise}

Inicialmente, o conteúdo e o processo (sequência de atividades) da análise de investimentos são construídos tendo como referência um modelo clássico de análise.
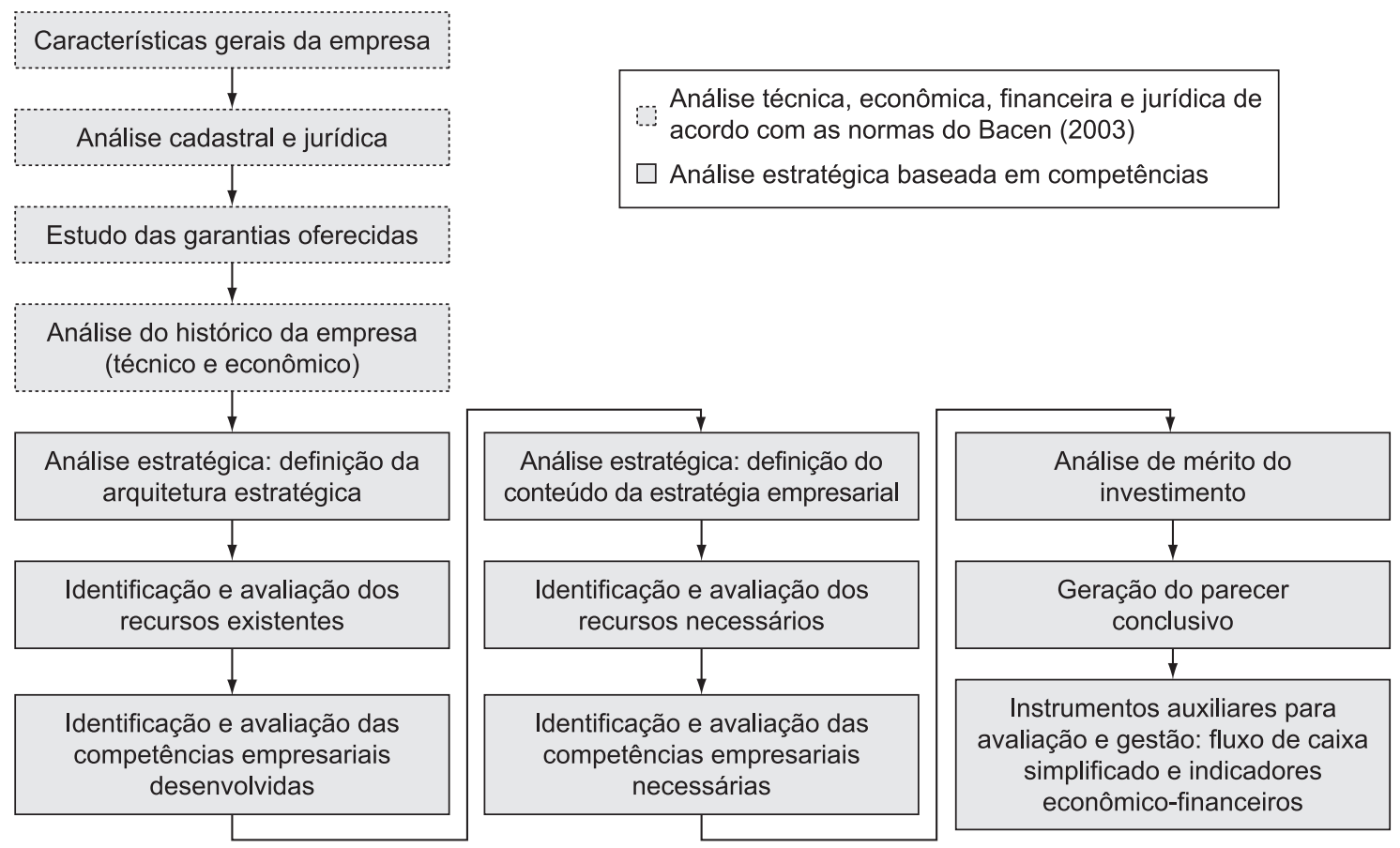

Figura 1. Processo de análise de investimento. Fonte: elaborado pelos autores. 
A partir desta estrutura lógica, incorporam-se etapas para a análise estratégica e o estudo e valoração de recursos e competências organizacionais. $\mathrm{O}$ processo proposto é refinado a partir de um conjunto de entrevistas com especialistas (acadêmicos e analistas 'plenos' de projetos). Uma síntese destas entrevistas é mostrada no Quadro 2. O resultado é um processo refinado e ajustado para ser testado em diferentes situações, conforme descrito sucintamente no Quadro 3. As simulações ou testes são apresentados resumidamente nos Quadros 10 a 12.

Foram desenvolvidas entrevistas com três analistas de projetos de investimento e com três acadêmicos das áreas de gestão estratégica de operações e gestão econômica da produção. Essencialmente, as entrevistas discutiram o processo de análise de investimento proposto na Figura 1 e descrito no Quadro 3, bem como a avaliação dos procedimentos que constam dos Quadros 7 e 8 no que se refere à sua factibilidade, usabilidade e utilidade. Entende-se por factibilidade se os procedimentos propostos são possíveis de serem realizados. A usabilidade avalia a facilidade de utilização dos procedimentos. E finalmente, a utilidade questiona a relevância de se realizar determinados procedimentos ou operações.

$O$ roteiro de entrevista utilizado envolve, em termos gerais, os seguintes tópicos: levantar e avaliar o estado atual das técnicas e processos utilizados para a análise de investimento, identificado na parte 'a' do Quadro 2; um estudo pormenorizado do processo e procedimentos propostos para a avaliação de competências organizacionais e a análise da arquitetura estratégica, apresentado nas partes ' $b$ ' e 'c' do Quadro 2; e a avaliação e proposição de alterações no processo proposto que constam das observações e da parte 'd' do Quadro 2.

Considerando a avaliação realizada junto aos analistas e acadêmicos, destacam-se quatro alterações propostas para o processo inicial de análise (Figura 1):

- Elaboração de um procedimento para explicitação do valor, em termos absolutos, de cada recurso existente, bem como a projeção de valores referentes aos recursos a serem adquiridos.

- Construção de um quadro orientativo para definição das especificações mínimas a serem observadas em cada nível de competência identificado. Este quadro tem a finalidade de homogeneizar procedimentos e facilitar o processamento da análise.

- Retirada da etapa que trata da análise de mérito do investimento, pois os procedimentos propostos (valores de referência) não apresentam fundamentação teórica ou prática.
- Retirada da etapa que trata da elaboração dos instrumentos auxiliares para avaliação e gestão, isto é, do fluxo de caixa simplificado e de indicadores econômico-financeiros. Estes itens são contemplados na análise técnica, econômica, financeira e jurídica que é uma atividade obrigatória, de acordo com as normas do Banco Central do Brasil (2003).

As modificações propostas pelos entrevistados justificam-se pelas seguintes razões. Os itens 1 e 2 estão relacionados à especificação e valoração das competências, quer seja pelos seus elementos constituintes, quer seja pela determinação do seu nível de desenvolvimento. Determinar o nível de desenvolvimento das competências organizacionais desenvolvidas é um passo importante na avaliação do projeto de investimento. Os itens 3 e 4 simplificam o processo, ou seja, a retirada do item 3 indica que o procedimento de análise proposto complementa a avaliação de projetos de investimento, mas não substitui as técnicas tradicionais. $\mathrm{O}$ item 4 é redundante com as análises técnica, econômica, financeira e jurídica, que se encontram incorporadas aos processos de avaliação.

O Quadro 3 apresenta o processo de análise de projetos de investimento refinado após as entrevistas, relacionando para cada etapa as atividades e procedimentos operacionais a serem desenvolvidos.

A partir de um exemplo fictício apresentado nos Quadros 4, 5 e 6, é possível ilustrar os procedimentos da Etapa IV, na análise técnica, econômica, financeira e jurídica de um projeto de investimento. Particularmente o Quadro 4 representa um resumo de aplicação dos recursos solicitados e as respectivas fontes de financiamento.

O Quadro 5 apresenta um estudo de repercussão do investimento a ser realizado, no desempenho econômico de uma empresa genérica, em um horizonte de 5 anos (exemplo fictício).

O Quadro 6 apresenta de forma simplificada a estrutura do capital social de uma empresa (exemplo fictício).

O Quadro 7 apresenta uma estrutura para a identificação e avaliação de recursos, composto por folhas de tarefa para definir o 'valor' (a), a 'sustentatibilidade' e a 'versatilidade' de um recurso. Este conjunto de procedimentos se aplica tanto aos recursos possuídos pela empresa (recursos existentes), como também para os recursos a serem adquiridos (recursos necessários). Identificar e avaliar os recursos constituem um importante processo para a identificação das competências necessárias à realização de determinada estratégia.

O uso do Quadro 7 é sumarizado por meio da pontuação total do recurso, em que: a escala de 
Quadro 2. Observações do processo de entrevistas.

(a) Técnicas de análise de investimento

\begin{tabular}{|ll|}
\hline \multicolumn{1}{|c|}{ Tópico } & \multicolumn{1}{c|}{ Observações } \\
\hline $\begin{array}{l}\text { Tempo médio de } \\
\text { entrevista }\end{array}$ & 1h15 \\
$\begin{array}{l}\text { Conhecimento dos } \\
\text { processos e técnicas de } \\
\text { análise de projetos de } \\
\text { investimento }\end{array}$ & $\begin{array}{l}\text { Os analistas de projeto declararam conhecer somente técnicas quantitativas, enquanto que } \\
\text { na organização e estrutura industrial e em estudos da cadeia de valor. }\end{array}$ \\
$\begin{array}{l}\text { Confiabilidade das } \\
\text { técnicas e processos } \\
\text { conhecidos }\end{array}$ & $\begin{array}{l}\text { Nenhum dos analistas considerou haver um método absolutamente confiável, opinião } \\
\text { compartilhada por dois acadêmicos. Um acadêmico considera as técnicas de análise } \\
\text { multicritério absolutamente confiáveis. }\end{array}$ \\
$\begin{array}{l}\text { Viabilidade para a } \\
\text { pesquisa de novos } \\
\text { processos de análise }\end{array}$ & $\begin{array}{l}\text { Todos os entrevistados consideraram viável a pesquisa para novos processos ou } \\
\text { 'qualificação' dos processos e procedimentos existentes. } \\
\begin{array}{l}\text { Conhecimento da } \\
\text { teoria baseada em } \\
\text { recursos, capacitações } \\
\text { e competências }\end{array}\end{array} \quad \begin{array}{l}\text { Somente um analista declarou conhecer a teoria baseada em recursos, capacitações e } \\
\text { competências, enquanto que todos os acadêmicos afirmaram ter familiaridade com elas. }\end{array}$ \\
\hline
\end{tabular}

(b) Processos e procedimentos propostos: análise de competências

Tópico

Análise estratégica:

definição da

arquitetura estratégica

Identificação e avaliação dos recursos existentes

Identificação e avaliação das competências empresariais desenvolvidas

\section{Observações}

Dois analistas consideram os procedimentos propostos adequados e suficientes para a análise da arquitetura estratégica, enquanto que um os considerou adequados, mas insuficientes.

Dois acadêmicos consideraram os procedimentos propostos adequados, mas insuficientes, sendo que o terceiro os considerou inadequados.

Como a maioria dos entrevistados considerou os procedimentos propostos adequados, estes foram mantidos no processo refinado.

Dois analistas consideraram os procedimentos propostos adequados e suficientes, sendo que o terceiro os considerou adequados e insuficientes.

Um acadêmico considerou os procedimentos propostos adequados e suficientes, enquanto que os outros dois os consideraram adequados, mas insuficientes.

Como a maioria das opiniões resultou na adequabilidade do processo, apesar de metade dos entrevistados considerarem que outras verificações poderiam ser úteis, manteve-se no processo final a formulação original para testá-la nos casos.

Os três analistas consideraram adequados e suficientes os procedimentos propostos, apesar de indicarem a necessidade de melhores especificações para a determinação dos níveis de competências existentes, visto que a Teoria baseada em Recursos, Capacitações e Competências não é amplamente conhecida (como verificado anteriormente) no meio dos analistas de projetos de investimento.

Os acadêmicos apresentaram opiniões divergentes, um considerou os procedimentos propostos adequados e suficientes, enquanto que outro os considerou adequados e insuficientes. $\mathrm{O}$ terceiro acadêmico considerou os procedimentos insuficientes por não desenvolverem a análise no nível individual (atitudes, conhecimentos e habilidades pessoais).

Considerando que a maioria dos entrevistados considerou os procedimentos propostos adequados, eles foram mantidos. Entretanto, os níveis de competências foram resumidamente explicitados no próprio formulário, com o propósito de proporcionar uma melhor compreensão. 
Quadro 2. Continuação.

(c) Processos e procedimentos propostos: arquitetura estratégica

\section{Tópico}

Análise estratégica:

definição do conteúdo

da estratégia

empresarial - SWOT

Análise estratégica:

definição do conteúdo

da estratégia

empresarial - áreas de

decisão

Identificação e

avaliação dos recursos

necessários

Identificação e

avaliação das

competências

empresariais

necessárias

\section{Observações}

Os três analistas consideraram os procedimentos propostos adequados e suficientes; opinião corroborada por um dos acadêmicos. Os outros dois acadêmicos os consideraram adequados, mas insuficientes.

Diante das posições estabelecidas, os procedimentos foram mantidos.

Os três analistas consideraram os procedimentos propostos adequados e suficientes.

Dois acadêmicos consideraram os procedimentos propostos adequados, enquanto que o terceiro os considerou inadequados e insuficientes.

Considerando os diferentes posicionamentos, optou-se por manter os procedimentos, testando-os nos casos.

Para confirmar os procedimentos propostos para a identificação e avaliação dos recursos existentes, questionaram-se novamente os procedimentos propostos para analisar recursos, desta vez, para analisar recursos a serem adquiridos.

Dois analistas consideraram os procedimentos propostos adequados e suficientes, sendo que o terceiro os considerou adequados e insuficientes.

Os três acadêmicos consideraram os procedimentos propostos adequados.

As respostas foram um pouco diferentes, no entanto, não implicaram alteração dos procedimentos propostos.

Os três analistas consideraram os procedimentos propostos adequados e suficientes.

Um acadêmico considerou os procedimentos propostos adequados, enquanto que os outros dois os consideram inadequados e insuficientes.

Identificou-se a necessidade de elaboração de um conjunto de procedimentos específicos, no entanto, decidiu-se testá-los nos casos, para então, propor modificações.

(d) Avaliação do processo proposto

Tópico

Análise de mérito do investimento

Factibilidade do processo

Necessidade de visita à empresa

Melhoria da coleta de dados

\section{Observações}

Dois analistas consideraram os procedimentos propostos adequados e suficientes, enquanto que o terceiro os considerou adequados e insuficientes.

Dois acadêmicos consideraram os procedimentos propostos adequados, enquanto que o terceiro os considerou inadequados e insuficientes.

Considerando as observações referentes às dificuldades de estabelecimento da valoração de mérito por intermédio de números absolutos (mudança de níveis de competência), adotou-se uma análise resumo analítica, referente às alterações dos níveis de competência das empresas.

Todos os entrevistados consideraram o processo proposto factível.

Todos os entrevistados consideraram essencial visitas à empresa em um processo de análise de investimento para expansão.

Para três analistas e dois acadêmicos, o processo proposto melhora a coleta de dados para o processo de análise, contudo para um dos acadêmicos o processo não permite qualquer melhora para a obtenção de informações. Outros meios indicados para melhorar a coleta de dados, particularmente no que se referem às visitas, foram o estudo prévio da empresa e seu setor e a formulação de um check-list de informações a serem recuperadas.

Fonte: elaborado pelos autores. 
Quadro 3. Processo refinado.

(a) análise técnica, econômica, financeira e jurídica

\begin{tabular}{|c|c|c|c|}
\hline Etapas & Título & Descrição & Procedimentos operacionais \\
\hline I & $\begin{array}{l}\text { Características } \\
\text { gerais da } \\
\text { empresa }\end{array}$ & $\begin{array}{l}\text { Informações sobre } \\
\text { setor, segmento, } \\
\text { localização e área } \\
\text { de atuação }\end{array}$ & $\begin{array}{l}\text { Preenchimento de formulário com as seguintes informações: razão } \\
\text { social, CNPJ, data de fundação, endereço, município, UF, CEP, porte, } \\
\text { contato, telefone, fax, } e \text {-mail, principais atividades. }\end{array}$ \\
\hline II & $\begin{array}{l}\text { Análise } \\
\text { cadastral e } \\
\text { jurídica }\end{array}$ & $\begin{array}{l}\text { Desenvolvimento } \\
\text { dos procedimentos } \\
\text { de análise de } \\
\text { acordo com } \\
\text { normas do Banco } \\
\text { Central do Brasil } \\
(2003)\end{array}$ & $\begin{array}{l}\text { Descrição do projeto, aspectos técnicos, endereço do projeto, código } \\
\text { CNAE (Classificação Nacional de Atividades Econômicas), início da } \\
\text { operação comercial, atendimento à legislação ambiental. } \\
\text { Determinação do nível de risco, pontuação de risco e verificação de } \\
\text { informes. } \\
\text { Verificação da situação de impostos e obrigações. } \\
\text { Identificação da forma jurídica. }\end{array}$ \\
\hline III & $\begin{array}{l}\text { Estudo das } \\
\text { garantias } \\
\text { oferecidas }\end{array}$ & $\begin{array}{l}\text { O valor financiável } \\
\text { pode ser igual ao } \\
\text { valor das garantias }\end{array}$ & $\begin{array}{l}\text { Identificação da fonte de financiamento. Valor a ser financiado. } \\
\text { Custos (spread total, custo básico). Prazos (carência, amortização, } \\
\text { total). Forma de pagamento (carência, amortização). Garantias } \\
\text { (reais, fidejussórias). }\end{array}$ \\
\hline IV & $\begin{array}{l}\text { Características } \\
\text { do } \\
\text { investimento }\end{array}$ & Valor e finalidade & $\begin{array}{l}\text { Elaboração de um quadro resumo com a indicação dos investimentos } \\
\text { a serem realizados e as respectivas fontes de financiamento (ver } \\
\text { exemplo no Quadro 4). } \\
\text { Avaliação das repercussões do projeto (ver exemplo no Quadro 5). } \\
\text { Estudo da composição do capital social (ver exemplo no Quadro 6) }\end{array}$ \\
\hline $\mathrm{V}$ & $\begin{array}{l}\text { Histórico da } \\
\text { empresa }\end{array}$ & $\begin{array}{l}\text { Evolução do } \\
\text { desempenho } \\
\text { da empresa nos } \\
\text { últimos três } \\
\text { exercícios }\end{array}$ & $\begin{array}{l}\text { Avaliação econômico-financeira: balanços e balancetes (ativo corrente } \\
\text { - AC, ativo realizável a longo prazo - ARLP, ativo permanente - AP, } \\
\text { passivo circulante - PC, passivo exigível a longo prazo - PELP, } \\
\text { patrimônio líquido - PL); demonstrativo de resultados (receita bruta, } \\
\text { impostos e devoluções, receita operacional líquida - ROL, custo } \\
\text { dos produtos/serviços comercializados, despesas administrativas, } \\
\text { despesas financeiras, lucro operacional, lucro líquido, depreciações), } \\
\text { fatores de avaliação (margem de garantia, grau de endividamento, } \\
\text { grau de imobilizações, liquidez seca, liquidez corrente, liquidez total, } \\
\text { lucratividade, rentabilidade, geração líquida de caixa). } \\
\text { Avaliação gerencial. } \\
\text { Avaliação do mercado atual e futuro. Principais concorrentes. } \\
\text { Principais clientes. Retrospecto de vendas. Projeção de vendas. } \\
\text { Projeção da capacidade de pagamentos. }\end{array}$ \\
\hline
\end{tabular}

(b) identificação e avaliação de recursos e competências

\begin{tabular}{|c|c|c|c|}
\hline Etapas & Título & Descrição & Procedimentos operacionais \\
\hline VI & $\begin{array}{l}\text { Análise estratégica: } \\
\text { definição da } \\
\text { arquitetura } \\
\text { estratégica }\end{array}$ & $\begin{array}{l}\text { Definição das } \\
\text { características gerais da } \\
\text { organização e gestão da } \\
\text { estratégia empresarial. }\end{array}$ & $\begin{array}{l}\text { Identificação das seguintes informações: responsável } \\
\text { pelo processo, participantes do processo, organização } \\
\text { do processo (modelos, cronogramas etc.), partes da } \\
\text { organização analisadas e fontes de dados utilizadas. }\end{array}$ \\
\hline VII & $\begin{array}{l}\text { Identificação e } \\
\text { avaliação dos } \\
\text { recursos existentes }\end{array}$ & $\begin{array}{l}\text { Identificação a avaliação } \\
\text { dos recursos existentes: } \\
\text { valor, sustentabilidade e } \\
\text { versatilidade. }\end{array}$ & $\begin{array}{l}\text { Identificação dos recursos considerados estratégicos para } \\
\text { a empresa. } \\
\text { Utilização dos Quadros } 7 \text { (a), (b) e (c) para a avaliação } \\
\text { dos recursos quanto a valor, sustentabilidade e } \\
\text { versatilidade. }\end{array}$ \\
\hline VIII & $\begin{array}{l}\text { Identificação e } \\
\text { avaliação das } \\
\text { competências } \\
\text { empresariais } \\
\text { desenvolvidas }\end{array}$ & $\begin{array}{l}\text { Identificação, declaração } \\
\text { e avaliação das } \\
\text { competências existentes. }\end{array}$ & $\begin{array}{l}\text { O Quadro } 8 \text { permite declarar e avaliar as competências } \\
\text { em termos de: aprendizado coletivo/troca de informações; } \\
\text { possibilidades de imitação; vantagens oferecidas aos } \\
\text { clientes; complementação de outras capacitações; } \\
\text { desenvolvimento de novos produtos/processos. } \\
\text { As medidas de avaliação se referem aos níveis de } \\
\text { desenvolvimento: necessário, em desenvolvimento, } \\
\text { desenvolvido e essencial. } \\
\text { O Quadro } 9 \text { contribui para a especificação ou declaração } \\
\text { de competências. }\end{array}$ \\
\hline
\end{tabular}


Quadro 3. Continuação.

\begin{tabular}{|c|c|c|c|}
\hline \multicolumn{4}{|c|}{ (c) análise estratégica } \\
\hline Etapas & Título & Descrição & Procedimentos operacionais \\
\hline \multirow[t]{2}{*}{ IX } & $\begin{array}{l}\text { Análise } \\
\text { estratégica: } \\
\text { definição do } \\
\text { conteúdo da }\end{array}$ & $\begin{array}{l}\text { Análise SWOT } \\
\text { da estratégia } \\
\text { empresarial. }\end{array}$ & $\begin{array}{l}\text { Elaboração de uma matriz estratégica: oportunidades e ameaças, } \\
\text { pontos fortes e pontos fracos. }\end{array}$ \\
\hline & $\begin{array}{l}\text { estratégia } \\
\text { empresarial }\end{array}$ & $\begin{array}{l}\text { Estudo da } \\
\text { estratégia de } \\
\text { operações. }\end{array}$ & $\begin{array}{l}\text { Identificação das políticas e ações desenvolvidas nas áreas de } \\
\text { decisão (estrutura: capacidade, instalações, tecnologia de processo } \\
\text { e integração vertical; infraestrutura: controle e planejamento da } \\
\text { produção, políticas de qualidade, estrutura organizacional, recursos } \\
\text { humanos, desenvolvimento de novos produtos e sistema de medição } \\
\text { de desempenho). } \\
\text { Identificação e customização dos objetivos de desempenho (preço/ } \\
\text { custo, qualidade, desempenho de entrega, flexibilidade e inovação). }\end{array}$ \\
\hline
\end{tabular}

(d) projeção de aquisição e desenvolvimento de recursos e competências

\begin{tabular}{|c|c|c|c|}
\hline Etapas & Título & Descrição & Procedimentos operacionais \\
\hline $\mathrm{X}$ & $\begin{array}{l}\text { Identificação } \\
\text { e avaliação } \\
\text { dos recursos } \\
\text { necessários }\end{array}$ & $\begin{array}{l}\text { Identificação e } \\
\text { avaliação dos } \\
\text { recursos a serem } \\
\text { adquiridos: valor, } \\
\text { sustentabilidade e } \\
\text { versatilidade. }\end{array}$ & $\begin{array}{l}\text { Identificação dos recursos considerados estratégicos para } \\
\text { aquisição. } \\
\text { Utilização dos Quadros } 7 \text { (a), (b) e (c) para a avaliação dos } \\
\text { recursos quanto a valor, sustentabilidade e versatilidade. }\end{array}$ \\
\hline XI & $\begin{array}{l}\text { Identificação e } \\
\text { avaliação das } \\
\text { competências } \\
\text { empresariais } \\
\text { necessárias }\end{array}$ & $\begin{array}{l}\text { Identificação, } \\
\text { declaração e } \\
\text { avaliação das } \\
\text { competências } \\
\text { a serem } \\
\text { desenvolvidas. }\end{array}$ & $\begin{array}{l}\text { O Quadro } 8 \text { especifica as competências a serem desenvolvidas } \\
\text { em termos de: aprendizado coletivo/troca de informações; } \\
\text { possibilidades de imitação; vantagens oferecidas aos clientes; } \\
\text { complementação de outras capacitações; desenvolvimento de } \\
\text { novos produtos/processos. } \\
\text { As medidas de avaliação se referem aos níveis de } \\
\text { desenvolvimento: necessário, em desenvolvimento, desenvolvido } \\
\text { e essencial. } \\
\text { O Quadro } 9 \text { contribui com a atribuição de significados aos níveis } \\
\text { de desenvolvimento de competências. }\end{array}$ \\
\hline \multicolumn{4}{|c|}{ (e) elaboração do parecer conclusivo } \\
\hline Etapas & Título & Descrição & Procedimentos operacionais \\
\hline XIII & $\begin{array}{l}\text { Geração } \\
\text { do parecer } \\
\text { conclusivo }\end{array}$ & $\begin{array}{l}\text { Conclusão da análise } \\
\text { de investimento com } \\
\text { a geração de um } \\
\text { parecer conclusivo } \\
\text { em relação ao projeto } \\
\text { de investimento. }\end{array}$ & $\begin{array}{l}\text { O parecer será estabelecido em termos: favorável ou não } \\
\text { favorável. } \\
\text { O parecer também inclui uma análise resumo analítica, } \\
\text { referente às alterações dos níveis de competência das empresas. }\end{array}$ \\
\hline
\end{tabular}

Fonte: elaborado pelos autores.

Quadro 4. Quadro de usos e fontes.

\begin{tabular}{|c|c|c|}
\hline Usos & $\mathbf{R} \$$ & $\%$ \\
\hline \multicolumn{3}{|l|}{ Construções civis } \\
\hline Equipamentos nacionais & $112.454,00$ & 60,40 \\
\hline Móveis e utensílios & $73.726,00$ & 39,60 \\
\hline Total de investimentos fixos & $186.180,00$ & 100,00 \\
\hline \multicolumn{3}{|l|}{ Capital de giro } \\
\hline Total & $186.180,00$ & 100,00 \\
\hline \multicolumn{3}{|l|}{ Fontes } \\
\hline Geração interna & $44.683,00$ & 24,00 \\
\hline \multicolumn{3}{|l|}{ Aumento de capital } \\
\hline BNDES/Aut-Fixo & $141.497,00$ & 76,00 \\
\hline Total & $186.180,00$ & 100,00 \\
\hline
\end{tabular}


Quadro 5. Repercussões.

\begin{tabular}{|lccc|}
\hline \multicolumn{1}{|c}{ Repercussões } & Unidade & Exercício: 2001 & Após o Projeto: 2006 \\
\hline Capacidade instalada & $\mathrm{R} \$$ & $2.212 .548,00$ & $3.451 .576,00$ \\
Mão de obra empregada & Postos & 27 & 49 \\
Faturamento & $\mathrm{R} \$$ & $2.212 .548,00$ & $3.451 .576,00$ \\
ICMS gerado & $\mathrm{R} \$$ & $65.613,00$ & $102.357,00$ \\
\hline
\end{tabular}

Fonte: elaborado pelos autores.

Quadro 6. Capital Social.

\begin{tabular}{|ccccc|}
\hline Na data de: & Autorizado & Subscrito & Integralizado & Votante \\
\hline $03 / 07 / 2002$ & $319.000,00$ & $319.000,00$ & $319.000,00$ & $319.000,00$ \\
\hline
\end{tabular}

Fonte: elaborado pelos autores.

Quadro 7. Identificação e avaliação de recursos.

\begin{tabular}{|c|c|c|c|c|c|c|}
\hline \multicolumn{7}{|l|}{ (a) valor } \\
\hline \multirow{2}{*}{$\begin{array}{l}\text { O recurso é valioso? } \\
\text { Qual é o efeito do } \\
\text { recurso sobre os custos } \\
\text { organizacionais e vendas? }\end{array}$} & \multicolumn{6}{|c|}{ Recurso: } \\
\hline & $\begin{array}{c}\text { Alto } \\
\text { impacto } \\
\text { negativo }\end{array}$ & & $\begin{array}{l}\text { Nenhum } \\
\text { impacto }\end{array}$ & & $\begin{array}{l}\text { Alto } \\
\text { impacto } \\
\text { positivo }\end{array}$ & $\begin{array}{l}\text { Não } \\
\text { conhecido }\end{array}$ \\
\hline & 1 & 2 & 3 & 4 & 5 & N.A. \\
\hline & ( ) & ( ) & ( ) & ( ) & ( ) & ( ) \\
\hline \multirow{3}{*}{$\begin{array}{l}\text { Qual é o efeito do recurso } \\
\text { sobre as capacitações } \\
\text { organizacionais para diminuir } \\
\text { ameaças ou capitalizar } \\
\text { oportunidades? }\end{array}$} & $\begin{array}{c}\text { Alto } \\
\text { impacto } \\
\text { negativo }\end{array}$ & & $\begin{array}{l}\text { Nenhum } \\
\text { impacto }\end{array}$ & & $\begin{array}{l}\text { Alto } \\
\text { impacto } \\
\text { positivo }\end{array}$ & $\begin{array}{l}\text { Não } \\
\text { conhecido }\end{array}$ \\
\hline & 1 & 2 & 3 & 4 & 5 & N.A. \\
\hline & ( ) & ( ) & ( ) & ( ) & ( ) & ( ) \\
\hline \multirow[t]{3}{*}{$\begin{array}{l}\text { As empresas concorrentes } \\
\text { possuem o recurso? }\end{array}$} & $\begin{array}{l}\text { Todos têm o } \\
\text { recurso }\end{array}$ & $\begin{array}{l}\text { A maioria } \\
\text { tem }\end{array}$ & $50 \%$ têm & Alguns têm & $\begin{array}{l}\text { Nenhum } \\
\text { tem }\end{array}$ & $\begin{array}{l}\text { Não } \\
\text { conhecido }\end{array}$ \\
\hline & 1 & 2 & 3 & 4 & 5 & N.A. \\
\hline & ( ) & ( ) & ( ) & ( ) & ( ) & ( ) \\
\hline \multirow[t]{3}{*}{$\begin{array}{l}\text { Que nível de desempenho } \\
\text { ele oferece em relação aos } \\
\text { concorrentes? }\end{array}$} & $\begin{array}{l}\text { Bem abaixo } \\
\text { da média da } \\
\text { indústria }\end{array}$ & $\begin{array}{l}\text { Abaixo da } \\
\text { média da } \\
\text { indústria }\end{array}$ & $\begin{array}{l}\text { Média para } \\
\text { a indústria }\end{array}$ & $\begin{array}{l}\text { No nível dos } \\
\text { melhores }\end{array}$ & $\begin{array}{l}\text { A melhor } \\
\text { média }\end{array}$ & $\begin{array}{l}\text { Não } \\
\text { conhecido }\end{array}$ \\
\hline & 1 & 2 & 3 & 4 & 5 & N.A. \\
\hline & ( ) & ( ) & ( ) & ( ) & ( ) & ( ) \\
\hline
\end{tabular}


Quadro 7. (Continuação).

\begin{tabular}{|c|c|c|c|c|c|c|}
\hline \multirow{2}{*}{$\begin{array}{l}\text { O recurso é sustentável? } \\
\text { Os concorrentes reconhecem } \\
\text { o recurso? }\end{array}$} & \multicolumn{6}{|c|}{ Recurso: } \\
\hline & Facilmente & & $\begin{array}{l}\text { Nenhum } \\
\text { impacto }\end{array}$ & & $\begin{array}{l}\text { Não é } \\
\text { reconhecido }\end{array}$ & $\begin{array}{c}\text { Não } \\
\text { conhecido }\end{array}$ \\
\hline & 1 & 2 & 3 & 4 & 5 & N.A. \\
\hline & ( ) & ( ) & ( ) & ( ) & ( ) & ( ) \\
\hline \multirow[t]{3}{*}{$\begin{array}{l}\text { Quanto tempo leva para } \\
\text { imitá-lo? }\end{array}$} & $\begin{array}{l}\text { Menos de } \\
\text { um mês }\end{array}$ & & & & $\begin{array}{c}\text { Mais de } \\
\text { cinco anos }\end{array}$ & $\begin{array}{c}\text { Não } \\
\text { conhecido }\end{array}$ \\
\hline & 1 & 2 & 3 & 4 & 5 & N.A. \\
\hline & ( ) & ( ) & ( ) & ( ) & ( ) & ( ) \\
\hline \multirow[t]{3}{*}{$\begin{array}{l}\text { Quanto custará imitar os } \\
\text { recursos? }\end{array}$} & $\begin{array}{l}\text { Menos de } \\
1 \% \text { das } \\
\text { vendas }\end{array}$ & & & & $\begin{array}{l}\text { Mais de } 5 \% \\
\text { das vendas }\end{array}$ & $\begin{array}{c}\text { Não } \\
\text { conhecido }\end{array}$ \\
\hline & 1 & 2 & 3 & 4 & 5 & N.A. \\
\hline & ( ) & ( ) & ( ) & ( ) & ( ) & ( ) \\
\hline \multirow{3}{*}{$\begin{array}{l}\text { Sem investimentos de tempo } \\
\text { ou dinheiro, quão rápido seu } \\
\text { valor declinará? }\end{array}$} & $\begin{array}{c}\text { Mais de } \\
50 \% \text { por ano }\end{array}$ & & & & $\begin{array}{l}\text { Menos de } \\
10 \% \text { por ano }\end{array}$ & $\begin{array}{l}\text { Não } \\
\text { conhecido }\end{array}$ \\
\hline & 1 & 2 & 3 & 4 & 5 & N.A. \\
\hline & ( ) & ( ) & ( ) & ( ) & ( ) & ( ) \\
\hline \multirow[t]{3}{*}{$\begin{array}{l}\text { Pode a vantagem competitiva } \\
\text { produzida pelo recurso ser } \\
\text { substituída? }\end{array}$} & $\begin{array}{c}\text { Sim, } \\
\text { em uma } \\
\text { extensão } \\
\text { significativa }\end{array}$ & & Parcialmente & & $\begin{array}{l}\text { Não } \\
\text { totalmente }\end{array}$ & $\begin{array}{l}\text { Não } \\
\text { conhecido }\end{array}$ \\
\hline & 1 & 2 & 3 & 4 & 5 & N.A. \\
\hline & ( ) & ( ) & ( ) & ( ) & ( ) & ( ) \\
\hline
\end{tabular}

\begin{tabular}{|c|c|c|c|c|c|c|}
\hline \multicolumn{7}{|l|}{ (c) versatilidade } \\
\hline \multirow{3}{*}{\begin{tabular}{|c|} 
O recurso é versátil? \\
Quão fortemente o recurso é \\
vinculado a outros recursos?
\end{tabular}} & \multicolumn{6}{|c|}{ Recurso: } \\
\hline & Fortemente vinculado & & & & Mantém-se sozinho & Não conhecido \\
\hline & 1 & 2 & 3 & 4 & 5 & N.A. \\
\hline & ( ) & ( ) & ( ) & ( ) & ( ) & ( ) \\
\hline \multirow{3}{*}{$\begin{array}{l}\text { Quão bem o recurso é } \\
\text { compreendido? }\end{array}$} & Não é compreendido & & & & Completamente & Não conhecido \\
\hline & 1 & 2 & 3 & 4 & 5 & N.A. \\
\hline & ( ) & ( ) & ( ) & ( ) & ( ) & ( ) \\
\hline \multirow{3}{*}{$\begin{array}{l}\text { Ele pode ser usado em outras } \\
\text { partes da empresa? }\end{array}$} & Não pode ser transferido & & & & Amplamente usado & Não conhecido \\
\hline & 1 & 2 & 3 & 4 & 5 & N.A. \\
\hline & ( ) & ( ) & ( ) & ( ) & ( ) & ( ) \\
\hline \multirow{3}{*}{$\begin{array}{l}\text { Pode ser usado em outros } \\
\text { mercados? }\end{array}$} & Não pode ser transferido & & & & Amplamente usado & Não conhecido \\
\hline & 1 & 2 & 3 & 4 & 5 & N.A. \\
\hline & ( ) & ( ) & ( ) & ( ) & ( ) & ( ) \\
\hline
\end{tabular}

Fonte: Mills et al. (2002). 
valorização de recursos vai de 4 a 20 pontos; a escala de sustentabilidade de recursos vai de 5 a 25 pontos; e a escala de versatilidade de recursos vai de 4 a 20 pontos. Tais faixas representam um somatório das notas dos diferentes indicadores, nas três categorias (valor, sustentabilidade e versatilidade), observando-se a escala de Likert de 5 pontos proposta por Mills et al. (2002). Sendo assim, a pontuação de recursos pode atingir um total entre 13 e 65 pontos. Esta pontuação permite avaliar a importância global dos recursos e compará-los. A comparação pode ser feita entre os recursos existentes na empresa, definindo para eles um valor estratégico, ou pode ser usada na priorização para aquisição de um novo recurso.

O Quadro 8 identifica, declara e avalia as competências organizacionais e constitui um importante elemento para a avaliação estratégica do investimento na medida em que identifica a capacidade de uma empresa em realizar uma determinada estratégia. A identificação das competências existentes e de seu nível de desenvolvimento permite uma avaliação qualitativa do potencial da empresa em gerar resultados em determinadas áreas de negócio.

O Quadro 9 serve como apoio para o preenchimento do Quadro 8. Neste quadro há uma definição dos níveis para cada aspecto avaliado nas competências organizacionais. Este quadro busca dar significado à escala de quatro níveis que descreve os níveis de competência.

Uma vez refinado o processo de análise, ele foi testado em um conjunto de três casos. Tais casos contribuíram para o esclarecimento de alguns pontos que não puderam ser esclarecidos no processo de entrevistas.

\section{Teste do processo de análise}

Foram utilizadas informações de três organizações pertencentes ao segmento de pequenas e médias empresas. Selecionaram-se empresas que demonstrassem aumento na participação do mercado local e que houvessem projetado investimentos nos últimos três anos. Deve ser destacado que estas empresas já haviam sido analisadas utilizando os procedimentos rotineiros, ou seja, sem o uso da análise estratégica baseada em competências. Diferencia-se a aplicação por setores, por meio de um estudo em empresa comercial, denominada empresa $X$; outro estudo em empresa industrial, denominada $Y$; e um terceiro estudo em empresa prestadora de serviços, denominada Z. Por intermédio dos casos selecionados, busca-se explorar diferentes tipos de empreendimentos, em setores econômicos distintos e que representam uma demanda significativa, em termos de projetos de investimento para expansão, no banco de desenvolvimento estudado. O Quadro 10 apresenta os projetos analisados.

Os procedimentos desenvolvidos para o processo de análise de investimento foram aplicados às três empresas e sucintamente apresentados nos Quadros 11 a 13.

Observa-se, na síntese de resultados apresentados no Quadro 11, que a integração dos recursos, objeto do financiamento, ao processo de formação de competências em operações de compras e de vendas, constitui o fundamento da avaliação de mérito.

Do Quadro 12 observa-se, como também apresentado no Quadro 11, que o investimento de propõe ao aumento de um nível na escala de competências. Tal fato também apoia fortemente a avaliação de mérito.

O Quadro 13 estabelece um contraponto às análises anteriores, pois não há uma vinculação direta dos recursos a serem adquiridos com o desenvolvimento das competências essenciais no empreendimento analisado. Tal fato constitui o argumento fundamental na avaliação negativa de mérito do projeto de investimento.

O Quadro 14 apresenta um resumo comparativo da aplicação dos dois processos de análise de investimento.

O fundamento básico da avaliação estratégica de investimento baseada no desenvolvimento de competências é a vinculação dos recursos a serem adquiridos com o aumento no nível de competências. Tais competências devem ser consideradas fundamentais sob o ponto de vista da estratégia adotada pelas empresas. Um banco de desenvolvimento pode pautar a sua carteira de projetos em ações que promovam o aumento da competitividade dos empreendimentos assistidos, e este fato fundamenta o parecer desfavorável à empresa 'Z'. Observa-se, porém, que a análise tradicional baseada em garantias e na capacidade de pagamento não identifica tal aspecto.

O Quadro 15 apresenta um conjunto de vantagens comparativas na aplicação do processo proposto para a análise de investimento. $\mathrm{O}$ desenvolvimento dos testes em casos já previamente analisados permite identificar as vantagens ou desvantagens resultantes da utilização adicional dos itens referentes à análise estratégica.

A possibilidade de utilizar estudos referentes à Teoria de Recursos, Capacitações e Competências neste trabalho estabelece, ainda que de maneira exploratória, uma nova abordagem de análise. Sendo assim, não se podem tirar conclusões definitivas a respeito do processo proposto.

A realização prática de simulações prova que estudos mais aprofundados no campo teórico poderão fazer com que o modelo evolua e, aliado a novos testes, 
Quadro 8. Identificação de competências existentes.

Competência:

Recursos relacionados:

Somatório da pontuação dos recursos existentes:

Aspectos analisados

Nível inicial

Necessário Em desenvolvimento Desenvolvido Essencial

Aprendizado coletivo/troca de informações

Possibilidades de imitação

Vantagens oferecidas aos clientes

Complementação de outras capacitações

Desenvolvimento de novos produtos/processos

Fonte: adaptado de Mills et al. (2002).

Quadro 9. Especificação dos níveis de competências.

\begin{tabular}{|c|c|c|c|c|}
\hline Aspecto & $\begin{array}{c}\text { Competência } \\
\text { necessária }\end{array}$ & $\begin{array}{l}\text { Competência em } \\
\text { desenvolvimento }\end{array}$ & $\begin{array}{l}\text { Competência } \\
\text { desenvolvida }\end{array}$ & $\begin{array}{c}\text { Competência } \\
\text { essencial }\end{array}$ \\
\hline $\begin{array}{l}\text { Aprendizado } \\
\text { coletivo/troca de } \\
\text { informações }\end{array}$ & $\begin{array}{l}\text { Não há } \\
\text { envolvimento e } \\
\text { comprometimento } \\
\text { funcional. } \\
\text { Comunicação } \\
\text { hierarquizada }\end{array}$ & $\begin{array}{l}\text { Identificação pelo } \\
\text { corpo funcional } \\
\text { dos objetivos gerais } \\
\text { da organização. } \\
\text { Disponibilização de } \\
\text { meios de comunicação }\end{array}$ & $\begin{array}{l}\text { Pouco envolvimento } \\
\text { e comprometimento } \\
\text { do corpo funcional no } \\
\text { desenvolvimento das } \\
\text { operações e processos. } \\
\text { Nível inicial de } \\
\text { comunicação horizontal }\end{array}$ & $\begin{array}{l}\text { Alto nível de } \\
\text { envolvimento e } \\
\text { comprometimento do } \\
\text { corpo funcional no } \\
\text { desenvolvimento das } \\
\text { operações e processos. } \\
\text { Possibilidade efetiva } \\
\text { de comunicação entre } \\
\text { unidades e níveis } \\
\text { organizacionais. }\end{array}$ \\
\hline $\begin{array}{l}\text { Possibilidades de } \\
\text { imitação }\end{array}$ & $\begin{array}{l}\text { Operações/ } \\
\text { processos } \\
\text { adquiridos } \\
\text { no mercado. } \\
\text { Dependência de } \\
\text { terceiros para } \\
\text { modernização e } \\
\text { manutenção. }\end{array}$ & $\begin{array}{l}\text { Operações/processos } \\
\text { adquiridos no mercado } \\
\text { ou obtidos em acordos } \\
\text { de cooperação. } \\
\text { Dependência de } \\
\text { terceiros flexibilizada, } \\
\text { no que tange à } \\
\text { modernização e } \\
\text { manutenção. }\end{array}$ & $\begin{array}{l}\text { Operações/processos } \\
\text { adquiridos no mercado } \\
\text { ou obtidos em acordos } \\
\text { de cooperação } \\
\text { ou desenvolvidos } \\
\text { internamente, com } \\
\text { limitada participação } \\
\text { externa para } \\
\text { modernização e } \\
\text { manutenção. }\end{array}$ & $\begin{array}{l}\text { Operações/processos } \\
\text { desenvolvidos } \\
\text { necessariamente com } \\
\text { recursos internos. }\end{array}$ \\
\hline $\begin{array}{l}\text { Vantagens } \\
\text { oferecidas aos } \\
\text { clientes }\end{array}$ & Não percebida. & $\begin{array}{l}\text { Produto/serviço } \\
\text { comparável. }\end{array}$ & $\begin{array}{l}\text { Produto/serviço com } \\
\text { referência específica de } \\
\text { vantagem. }\end{array}$ & $\begin{array}{l}\text { Produto/serviço com } \\
\text { ampla referência de } \\
\text { vantagens. }\end{array}$ \\
\hline $\begin{array}{l}\text { Complementação } \\
\text { de outras } \\
\text { capacitações }\end{array}$ & $\begin{array}{l}\text { Operações/ } \\
\text { processos para } \\
\text { linha de produtos } \\
\text { tradicionais. }\end{array}$ & $\begin{array}{l}\text { Operações/processos } \\
\text { para melhoramento de } \\
\text { produtos tradicionais }\end{array}$ & $\begin{array}{l}\text { Operações/processos } \\
\text { para melhoramento } \\
\text { e diversificação de } \\
\text { produtos }\end{array}$ & $\begin{array}{l}\text { Operações/processos } \\
\text { para melhoramento, } \\
\text { diversificação e } \\
\text { criação de novos } \\
\text { produtos. }\end{array}$ \\
\hline $\begin{array}{l}\text { Desenvolvimento } \\
\text { de novos } \\
\text { processos/ } \\
\text { produtos }\end{array}$ & $\begin{array}{l}\text { Processos/produtos } \\
\text { permitindo } \\
\text { funcionamento } \\
\text { normal. }\end{array}$ & $\begin{array}{l}\text { Processos/produtos } \\
\text { próprios para } \\
\text { manutenção de } \\
\text { mercado. }\end{array}$ & $\begin{array}{l}\text { Processos/produtos } \\
\text { que possibilitem } \\
\text { diversificação no } \\
\text { mercado. }\end{array}$ & $\begin{array}{l}\text { Processos/produtos } \\
\text { que possibilitem } \\
\text { diversificação e } \\
\text { entrada em novos } \\
\text { mercados. }\end{array}$ \\
\hline
\end{tabular}

Fonte: elaborado pelos autores. 
Quadro 10. Características das empresas.

\begin{tabular}{|c|c|c|c|}
\hline & Empresa X & Empresa Y & Empresa Z \\
\hline Ano de fundação & 1989 & 1997 & 1996 \\
\hline Local de atividade & $\begin{array}{l}\text { Estado do Paraná - } \\
\text { Região norte }\end{array}$ & $\begin{array}{l}\text { Estado do Paraná - } \\
\text { Região oeste }\end{array}$ & $\begin{array}{l}\text { Estado do Paraná - } \\
\text { Região sul }\end{array}$ \\
\hline $\begin{array}{l}\text { Atividades } \\
\text { principais }\end{array}$ & $\begin{array}{c}\text { Comércio varejista/ } \\
\text { supermercado }\end{array}$ & $\begin{array}{l}\text { Fabricação de produtos } \\
\text { alimentícios/biscoitos }\end{array}$ & Prestado de serviços - clínica \\
\hline Capital social & $\mathrm{R} \$ 319.000,00$ & $\mathrm{R} \$ 800.000,00$ & $\mathrm{R} \$ 3.100 .000,00$ \\
\hline Receita em 2001 & $\mathrm{R} \$ 2.212 .548,00$ & $\mathrm{R} \$ 14.319 .000,00$ & $\mathrm{R} \$ 9.800 .000,00$ \\
\hline Ativo permanente & $\mathrm{R} \$ 203.000,00$ & $\mathrm{R} \$ 6.493 .000,00$ & $\mathrm{R} \$ 1.059 .000,00$ \\
\hline Instalações físicas & Área construída - 900,00 m² & Área construída - 4.600,00 m² & Área construída - 2.130,00 m² \\
\hline $\begin{array}{l}\text { Descrição do } \\
\text { projeto de } \\
\text { investimento }\end{array}$ & $\begin{array}{l}\text { Expansão da empresa no } \\
\text { mercado local, por meio } \\
\text { de investimento em nova } \\
\text { área de vendas no mesmo } \\
\text { município com área de } \\
504,00 \mathrm{~m}^{2} \text {, e instalação } \\
\text { de novos equipamentos } \\
\text { operacionais e de } \\
\text { informática. }\end{array}$ & $\begin{array}{c}\text { Expansão da empresa } \\
\text { no mercado local com } \\
\text { investimento para nova área } \\
\text { de expedição e armazenagem, } \\
\text { e administração - } \\
\text { totalizando um acréscimo de } \\
3.553,94 \mathrm{~m}^{2} \text {; e aquisição de } \\
\text { equipamentos para uma nova } \\
\text { linha de produção. }\end{array}$ & $\begin{array}{c}\text { Expansão da empresa } \\
\text { no mercado local, com } \\
\text { investimento em nova área para } \\
\text { prestação de atendimentos com } \\
8.003,48 \mathrm{~m}^{2} \text { a ser localizada em } \\
\text { terreno contíguo à sede atual. }\end{array}$ \\
\hline $\begin{array}{l}\text { Valor do } \\
\text { investimento }\end{array}$ & $\mathrm{R} \$ 186.180,00$ & $\mathrm{R} \$ 2.249 .224,00$ & $\mathrm{R} \$ 3.076 .560,00$ \\
\hline
\end{tabular}

Fonte: Banco de Desenvolvimento Estudado.

Quadro 11. Análise de competências e recursos da empresa ' $X$ '.

\begin{tabular}{|ll|}
\hline \multicolumn{1}{|c|}{ Análise de recursos e competências } & \multicolumn{1}{c|}{ Descrição } \\
\hline Competências identificadas & $1^{\text {a }}$ - Operações de compras \\
& $2^{\text {a }}$ - Operações de vendas \\
Número de alterações de níveis de competência & 1 nível por competência \\
Percentual de aumento de níveis de competência & $100 \%$ \\
Grupos de recursos utilizados & 4 grupos: humanos; construções civis; \\
& equipamentos e programas de informática; marca \\
Mérito do investimento & $\begin{array}{l}\text { Maior integração de recursos existentes, aumentando } \\
\text { sua utilização com os investimentos a serem realizados, } \\
\text { proporcionando aumento das operações de vendas, acesso a } \\
\text { novo mercado, contribuição ao cliente pela oferta de novos } \\
\text { serviços, imitação onerosa }\end{array}$ \\
&
\end{tabular}

Quadro 12. Análise de competências e recursos da empresa ' $Y$ '.

\begin{tabular}{|c|c|}
\hline Análise de recursos e competências & Descrição \\
\hline Competências identificadas & $\begin{array}{l}1^{\mathrm{a}}-\text { Operações de produção. } \\
2^{\mathrm{a}}-\text { Operações de vendas. }\end{array}$ \\
\hline Número de alterações de níveis de competência & 1 nível por competência \\
\hline Percentual de aumento de níveis de competência & $100 \%$ \\
\hline Grupos de recursos utilizados & $\begin{array}{l}4 \text { grupos: humanos; construções civis; máquinas e instalações; } \\
\text { equipamentos; e programas de informática }\end{array}$ \\
\hline Mérito do investimento & $\begin{array}{c}\text { Maior integração de recursos existentes, aumentando } \\
\text { sua utilização com os investimentos a serem realizados, } \\
\text { proporcionando aumento das operações de vendas, acesso a } \\
\text { novos mercados, contribuição ao cliente pela oferta de novos } \\
\text { produtos, imitação onerosa. }\end{array}$ \\
\hline
\end{tabular}


Quadro 13. Análise de competências e recursos da empresa ' $Z$ '.

\begin{tabular}{|ll|}
\hline \multicolumn{1}{|c|}{ Análise de recursos e competências } & \multicolumn{1}{c|}{ Descrição } \\
\hline Competências identificadas & $\begin{array}{l}1^{\text {a }} \text { - Pesquisa e desenvolvimento de procedimentos } \\
\text { operacionais; } \\
2^{\text {a }} \text { - Procedimentos operacionais. } \\
\text { Não foi verificado }\end{array}$ \\
$\begin{array}{l}\text { Número de alterações de níveis de competência } \\
\text { Percentual de aumento de níveis de competência }\end{array}$ & $\begin{array}{l}1 \text { grupo: Construções civis } \\
\text { Grupos de recursos utilizados }\end{array}$ \\
$\begin{array}{l}\text { Pouca integração de recursos existentes, aumentando } \\
\text { investimentos em aspectos puramente de aumento } \\
\text { de capacidade de atendimento. Haverá aumento de } \\
\text { possibilidade de realização de procedimentos, contudo não } \\
\text { haverá acesso a novo mercado, a contribuição ao cliente } \\
\text { será pela oferta de novas dependências, mas não novos } \\
\text { serviços, a imitação considera-se onerosa. }\end{array}$ \\
\hline
\end{tabular}

Quadro 14. Comparação de análises.

\begin{tabular}{|cccc|}
\hline Empresa & Parecer original & Parecer abordagem por competências & Justificativa \\
\hline $\mathrm{X}$ & Favorável & Favorável & $\begin{array}{c}\text { Acesso a novos mercados. } \\
\text { Contribuição ao cliente. } \\
\text { Difícil imitação. }\end{array}$ \\
$\mathrm{Y}$ & Favorável & Favorável & $\begin{array}{c}\text { Acesso a novos mercados. } \\
\text { Contribuição ao cliente. } \\
\end{array}$ \\
& Favorável & & Difícil imitação. \\
& & Desfavorável & Manutenção de mercado. \\
& & & Contribuição limitada. \\
& & Fácil imitação.
\end{tabular}

Fonte: elaborado pelos autores.

Quadro 15. Vantagens comparativas.

\begin{tabular}{|lcc|}
\hline \multicolumn{1}{|c}{ Fatores } & Análise Econômico-Financeira & $\begin{array}{c}\text { Abordagem Econômico- } \\
\text { Financeira-Competências }\end{array}$ \\
\hline Tempo para Processamento da Análise & Menor & Maior \\
Sistematização do Modelo & Similar & Similar \\
Recursos Materiais Necessários para & Similar & Similar \\
Processamento da Análise & & Com procedimentos metodológicos \\
Vistoria Física & Sem procedimentos metodológicos & Maior \\
Verificação de Aspectos Intangíveis & Menor & Não mensurável \\
Qualidade da Avaliação & Pequena & \\
\hline
\end{tabular}

Fonte: elaborado pelos autores.

permitirá o real estabelecimento de um novo processo de análise de crédito para financiamento de projetos de longo prazo. Tal fato contribui objetivamente para a melhoria do processo concessão de crédito para pequenas empresas, garantindo o alinhamento entre recursos, capacitações, competências, estratégia e desempenho, ou pelo menos, que o investimento seja realizado dentro destas premissas.

\section{Conclusões}

Foi realizado o desenvolvimento e teste de um processo para análise de investimento, estudado no âmbito de pequenas e médias empresas, tendo como objeto de estudo projetos de expansão. A organização do processo resultante está fundamentada nas seguintes etapas: análise técnica, econômica, financeira e jurídica; identificação e avaliação 
de recursos e competências; análise estratégica; projeção de aquisição e desenvolvimento de recursos e competências; e elaboração do parecer conclusivo.

Dado o caráter exploratório da pesquisa, observaram-se os requisitos adequados à técnica de 'triangulação', ou seja, assegurou-se a utilização de diversas fontes de evidência, garantindo constitutivamente a qualidade da pesquisa realizada. Foram realizadas três entrevistas com acadêmicos e três entrevistas com analistas de projetos, bem como foram testados os procedimentos propostos em três casos de simulação.

O processo desenvolvido utilizou uma abordagem estratégica baseada em recursos, definida no nível da função operações, para a melhoria de um processo amplamente utilizado no setor bancário. A área bancária deve acompanhar, para cumprir seus objetivos básicos de uma correta análise de um projeto de investimento produtivo, as evoluções constantes dos sistemas de produção. A abordagem proposta é um trabalho prospectivo, ou seja, um passo inicial para a melhoria dos procedimentos de análise, mas sem a pretensão de ser um trabalho final. Como constatado em todas as entrevistas realizadas, as pesquisas para melhoria dos procedimentos de análise de projetos de investimentos têm reconhecida importância para os setores acadêmico, produtivo e financeiro.

As limitações do processo proposto vinculam-se a aspectos metodológicos, de conteúdo e de formação do analista de investimento. A metodologia carece de mais testes comparativos, particularmente no que se refere à avaliação de recursos e competências. A discussão sobre o conteúdo do processo deve ser aprofundada, no sentido de se procurar estabelecer claramente relações de causalidade entre posicionamento competitivo, formação de competências organizacionais e recursos. O processo é relativamente complexo e necessita de uma preparação específica do analista de investimentos nas áreas de estratégia de negócios, estratégia de operações e visão baseada em recursos. É importante destacar que a análise estratégica baseada em competências organizacionais não substitui as técnicas tradicionais de análise de projetos de investimento, mas ela deve ser vista como um processo complementar para dar mais consistência, informação e 'robustez' ao processo de tomada de decisão.

Como evolução do trabalho, para que ele possa assumir um caráter normativo, propõe-se novamente recorrer à análise dos especialistas para os resultados das simulações, bem como a realização de novos testes. Deve-se também ampliar a perspectiva de aplicação para empresas de diferentes portes, bem como o acompanhamento longitudinal dos investimentos realizados, avaliando a evolução do desempenho econômico.

Fatores de qualidade devem ser aplicados para avaliar o desenvolvimento dos procedimentos, e estes devem englobar: a factibilidade dos procedimentos que foi verificada neste trabalho; a usabilidade em que se deve propor a utilização dos procedimentos por diferentes analistas de investimento; a utilidade que foi inicialmente avaliada pelos entrevistados, mas que necessita de um maior aprofundamento.

O desenvolvimento de processos para a avaliação de crédito deve se adequar à atual conjuntura econômica e mercadológica, contemplando assim o ambiente e a sua evolução, e também acompanhar o desenvolvimento dos processos produtivos e de seus sistemas de gestão.

\section{Referências}

ALVES, M. Como escrever teses e monografias. São Paulo: Campus, 2003.

ANDREWS, K. R. The concept of corporate strategy. Homewood: R. D. Irwin, 1980.

ANSOFF, I. A nova estratégia empresarial. São Paulo: Atlas, 1990.

BANCO CENTRAL DO BRASIL - BACEN. Manual de normas e instruções. Brasília, 2003.

BAND, W. A. Competências críticas: dez idéias para revolucionar a empresa. São Paulo: Campus, 1997.

BARNEY, J. Firm resources and sustained competitive advantage. Journal of Management, v. 17, n. 1, p. 99-120, 1991.

BOUCHER, X.; BONJOUR, E.; GRABOT, B. Formalisation and use of competencies for industrial performance optimisation: a survey. Computers in Industry, v. 58, n. 2, p. 98-117, 2007.

BRASIL, H. G. Avaliação moderna de investimentos. Rio de Janeiro: Qualitymark, 2002.

BROWN, S.; BESSANT, J. The manufacturing strategycapabilities links in mass customisation and agile manufacturing: an exploratory study. International Journal of Operations \& Production Management, v. 23, n. 7, p. 707-730, 2003.

BROWN, S.; BLACKMON, K. Aligning manufacturing strategy and business-level competitive strategy in new competitive environments: the case for strategic resonance. Journal of Management Studies, v. 42, n. 4, p. 793-815, 2005.

CASAROTTO FILHO, N. Projeto de negócio. São Paulo: Atlas, 2002.

CASAROTTO FILHO, N.; KOPITTKE, B. H. Análise de investimentos. 9. ed. São Paulo: Atlas, 2000.

CHANDLER, A. D.; McCRAW, T. K. Alfred Chandler: ensaios para uma teoria histórica da grande empresa. Rio de Janeiro: Fundação Getúlio Vargas, 1998.

CHAUMON, M. E. B.; DUBOIS, M.; RETOUR, D. L'acceptation des nouvelles technologies d'information: le cas des systèmes d'information en milieu bancaire. Psychologie du Travail et des Organisations, v. 12, n. 4, p. 247-262, 2006.

CHEN, Y.; WU, T. An empirical analysis of core competence for high-tech firms and traditional manufacturers. Journal of Management Development, v. 26, n. 2, p. 159-168, 2007. 
CHIESA, V.; MANZINI, R. Competence-based diversification. Long Range Planning, v. 30, n. 2, p. 209-217, 1997.

DAVIS, M. M.; AQUILANO, N. J.; CHASE, R. B. Fundamentos da administração da produção. São Paulo: Bookman, 1999.

DIMOVA, L.; SEVASTIANOV, P.; SEVASTIANOV, D. MCDM in a fuzzy setting: investment projects assessment application. International Journal of Production Economics, v. 100, n. 1, p. 10-29, 2006.

DREJER, A.; RIIS, J.O. Competence strategy. Copenhagen: Børsens Forlag, 2000.

ESCRIG-TENA, A. B.; BOU-LLUSAR, J. C. A model for evaluating organizational competencies: an application in the context of quality management initiative. Decision Sciences, v. 36, n. 2, p. 221-257, 2005.

ESTY, B. C. Modern project finance: a casebook. New York: John Wiley, 2008.

FERRAZ, J. C.; KUPFER, D.; HAGUENAUER, L. Made in Brazil: desafios competitivos para a indústria. São Paulo: Campus, 2001.

FLEURY, A. C. C.; FLEURY M. T. L. Estratégias competitivas e competências essenciais: perspectivas para a internacionalização da indústria no Brasil. Gestão e Produção, v. 10, n. 2, p. 129-144, 2003.

FLEURY, A. C. C.; FLEURY, M. T. L. Estratégias empresariais e formação de competências: um quebra-cabeça caleidoscópio da indústria brasileira. 3. ed. São Paulo: Atlas, 2004.

GAGNON, S. Resource-based competition and the new operations strategy. International Journal of Operations \& Production Management, v. 19, n. 2, p. 125-138, 1999.

GONZALEZ-BENITO, J. A study of the effect of manufacturing proactivity on business performance. International Journal of Operations \& Production Management, v. 25, n. 3, p. 222-241, 2005.

GÖTZE, U.; NORTHCOTT, D.; SCHUSTER, P. Investment appraisal: methods and models. Berlin: Springer Verlag, 2008.

HAYES, R. H.; WHEELWRIGHT, S. C. Restoring our competitive edge: competing through manufacturing. New York: John Wiley, 1984.

JURIE, J. D. Building capacity: organizational competence and critical theory. Journal of Organizational Change Management, v. 13, n. 3, p. 264-274, 2000.

KATHURIA, R.; PORTH, S. J. Strategy-managerial characteristics alignment and performance: a manufacturing perspective. International Journal of Operations \& Production Management, v. 23, n. 3, p. 255-276, 2003.

KETOKIVI, M.; SCHROEDER, R. Manufacturing practices, strategic fit and performance: a routine-based view. International Journal of Operations \& Production Management, v. 24, n. 2, p. 171-191, 2004.

LAMARQUE, E. Identifying key activities in banking firms: a competence-based analysis. Advances in Applied Business Strategy, v. 7, n. 1, p. 29-47, 2004.

LEACHMAN, C.; PEGELS, C. C.; SHIN, S. K. Manufacturing performance: evaluation and determinants.
International Journal of Operations \& Production Management, v. 25, n. 9, p. 851-874, 2005.

LEONG, G. K.; SNYDER, D. L.; WARD, P. T. Research in the process and content of manufacturing strategy. OMEGA, v. 18, n. 2, p. 109-122, 1990.

LEUNG, S.; LEE, W. B. Strategic manufacturing capability pursuance: a conceptual framework. Benchmarking: an International Journal, v. 11, n. 2, p. 156-174, 2004.

LEWIS, M. A. Analyzing organizational competence: implications for the managing of operations. International Journal of Operations \& Production Management, v. 23, n. 7, p. 731-756, 2003.

LEWIS, M. W. Iterative triangulation: a theory development process using existing case studies. Journal of Operations Management, v. 16, n. 4, p. 455-469, 1998.

MATHEUS, L. F. Fatores a serem considerados na estruturação do controle de projetos de investimento: uma abordagem da utilização do Balanced Scorecard. São Carlos: USP, 2000. 19 p.

MCGRATH, R. G.; MacMILLAN, I. C.; VENKATARAMAN, S. Defining and developing competence: a strategic process paradigm. Strategic Management Journal, v. 16, n. 4, p. 251-275, 1995.

MENOR, L. J.; ROTH, A. V. New service development competence in retail banking: construct development and measurement validation. Journal of Operations Management, v. 25, n. 4, p. 825-846, 2007.

MILLS, J. et al. Competing through competences. Cambridge: Cambridge University Press, 2002.

MILLS, J.; PLATTS, K.; BOURNE, M. Applying resourcebased theory: methods, outcomes and utility for managers. International Journal of Operations \& Production Management, v. 23, n. 2, p. 148-166, 2003b.

MILLS, J.; PLATTS, K.; BOURNE, M. Competence and resources architectures. International Journal of Operations \& Production Management, v. 23, n. 9, p. 977-994, 2003a.

O'REGAN, N.; GHOBADIAN, A. The importance of capabilities for strategic direction and performance. Management Decision, v. 42, n. 2, p. 292-312, 2004.

OLIVEIRA, D. P. R. Planejamento estratégico: conceitos, metodologias e práticas. 19. ed. São Paulo: Atlas, 2003.

PENROSE, E. The theory of the growth of the firm London: Basil Blackwell, 1959.

PLATTS, K. W. et al. Testing manufacturing strategy formulation processes. International Journal of Production Economics, v. 56-57, n. 1, p. 517-523, 1998.

POST, H. A. Building a strategy on competences. Long Range Planning, v. 30, n. 5, p. 733-740, 1997.

PRAHALAD, C. K.; HAMEL, G. The core competence of the corporation. Harvard Business Review, v. 68, n. 3, p. 79-91, 1990.

PURCELL, K. J.; GREGORY, M. J. Linking competence management and strategic planning in manufacturing organisations: an empirical investigation. Cambridge: ISMS, 1998.

QUINN, J. B. Strategies for change: logical incrementalism. Homewood: R. D. Irwin, 1980. 
RUSJAN, B. Model for manufacturing strategic decision making. International Journal of Operations and Production Management, v. 25, n. 8, p. 740-761, 2005.

SANCHEZ, R. Strategic management at the point of inflection: systems, complexity and competence theory. Long Range Planning, v. 30, n. 6, p. 939-946, 1997.

SANTOS, J. O. Análise de crédito: empresas e pessoas físicas. São Paulo: Atlas, 2000.

SCHMENNER, R.W.; VASTAG, G. Revisiting the theory of production competence: extensions and cross-validations. Journal of Operations Management, v. 24, n. 6, p. 893-909, 2006.

SILVA, J. P. Gestão e análise de risco de crédito. 3. ed. São Paulo: Atlas, 2000.

SLACK, N. Vantagem competitiva em manufatura: atingindo competitividade em operações industriais. 2. ed. São Paulo: Atlas, 2002.
STONEHOUSE, G.; PEMBERTON, J. Strategic planning in SMEs: some empirical findings. Management Decision, v. 40, n. 9, p. 853-861, 2002.

SWINK, M.; NARASIMHAN, R.; KIM, S. W. Manufacturing practices and strategy integration: effects on cost efficiency, flexibility, and market-based performance. Decision Sciences, v. 36, n. 3, p. 427-457, 2005.

UPTON, D. M.; MACADAM, S. R. Why (and how) to take a plant tour. Harvard Business Review, v. 75, n. 3, p. 97-106, 1997.

WERNERFELT, B. A resource-based view of the firm. Strategic Management Journal, v. 5, n. 2, p. 171-180, 1984.

WINTER, S. Knowledge and competence as strategic assets. In: TEECE, D. (Eds). The Competitive Challenge. Cambridge: Ballinger, 1987. p. 159-184.

WOILER, S.; MATHIAS, W. F. Projetos: planejamento, elaboração e análise. São Paulo: Atlas, 1985.

WRIGHT, P.; KROLL, M. K.; PARNELL, J. Administração estratégica: conceitos. São Paulo: Atlas, 2000. 